\title{
Coal Mine Gas Explosion Vulnerability Assessment Based on the “Glass Heart” Model
}

\author{
Shuicheng Tian $\mathbb{D}^{1,2}$ Pengfei Yang $\mathbb{D}^{1,2}$ and Kai Tang $\mathbb{D}^{1,2}$ \\ ${ }^{1}$ School of Safety Science and Engineering, Xi'an University of Science and Technology, Xi'an 710054, China \\ ${ }^{2}$ Institute of Safety and Emergency Management, Xi'an University of Science and Technology, Xi'an 710054, China \\ Correspondence should be addressed to Pengfei Yang; 1102925805@qq.com
}

Received 17 March 2021; Revised 10 April 2021; Accepted 13 April 2021; Published 24 April 2021

Academic Editor: Feng Xiong

Copyright ( 2021 Shuicheng Tian et al. This is an open access article distributed under the Creative Commons Attribution License, which permits unrestricted use, distribution, and reproduction in any medium, provided the original work is properly cited.

Gas explosion, which is the main type of accidents reported in coal mines, comes with serious economic and safety consequences. The present work adopts the "glass heart" model for assessing the vulnerability of coal mines to gas explosions based on a constructed gas explosion vulnerability assessment index system. The proposed index system is applied to a coal mine in Henan Province, China, as an example. The original disturbance index is augmented by including the energy release index factor. The Delphi method is employed by six experts to score the index factors according to a scoring standard. Data analysis and processing yield a gas explosion vulnerability score of 0.431 for the example mine. Accordingly, the mine is classified as grade II, indicating that the mine is likely to result in casualties and/or property loss. A comparison of the assessment results with those obtained via an analysis of records pertaining to previous gas explosion accidents indicates that the proposed assessment of gas explosion vulnerability by means of the "glass heart" assessment model is realistic. The "glass heart" vulnerability assessment method offers a new perspective and methodology for assessing the vulnerability of coal mines to gas explosion and conducting coal mine risk classification.

\section{Introduction}

Gas explosions are one of the main types of accidents in coal mines [1], and these come with very serious economic and safety consequences [2]. Gas explosions are affected by numerous complex and coupled factors with varying degrees of influence. This makes the identification and assessment of the various factors influencing gas explosions of great interest for ascertaining the vulnerability of coal mines to gas explosions.

This issue has been investigated in numerous studies. For example, Hatton and Whateley [3] established the factors influencing gas explosion in a coal mine according to geological factors, extension distance factors, roadway section factors, and roadway condition factors. These influencing factors were then applied to obtain a gas explosion assessment function, and the risk grade of coal mines was also determined according to the assessment criterion. Tauziède et al. [4] assessed the possibility of gas explosion as a result of gas emission in existing mines. Fothergill et al. [5] assessed the risk of gas explosion using computational fluid dynamic (CFD) software to simulate gas flow field characteristics in different regions of a mine under a turbulent flow state. The simulated gas explosion field generated in the model was demonstrated comparatively to be realistic and thereby provided a new method to determine the expected severity of gas explosions in coal mines. Marek et al. [6] applied a neural network technology to assess the risk of coal mine gas explosion via predictions of the gas emission from the working face of the coal mine. Wenchao [7] included a gas explosion safety coefficient developed according to the man-machineenvironment system and proposed a major gas explosion risk assessment model on the basis of the risk assessment on the working condition method. Xuan [8] proposed a formula for calculating the risk of gas explosion based on the gas overlimit frequency, gas emission intensity, and possible damage caused by accidents. Min [9] established a gas explosion hazard prediction index system based on a comprehensive analysis of the risk of gas explosion for a fully mechanized caving face according to the gas state and the man- 
machine-management system. The proposed prediction index system was employed to assess the risk of gas explosion for a fully mechanized caving face using a neural network technology. Yanping [10] analyzed the factors influencing the basic conditions of gas explosion based on three types of hazard theory and constructed a risk warning index system for coal mine gas explosions with 15 factors. Haifeng [11] incorporated 18 factors to construct an early warning risk index system for assessing the hazard associated with coal mine gas explosions based on three types of hazard theory. While past work has made excellent progress in the development of methods for conducting gas explosion assessment, no generally accepted index system is yet available for gas explosion assessment.

Hazard assessment is closely associated with the concept of vulnerability, which arose from research related to disaster science [12]. Presently, vulnerability has been applied in multiple interdisciplinary fields and has also been widely used in safety engineering for system safety assessment [13]. In terms of coal mine vulnerability assessments, $\mathrm{Wu}$ et al. [14-18] proposed five practical vulnerability index methods to assess coal seam floor water inrush through the Geographic Information System and other technologies. Liu et al. [19-21] identified and assessed vulnerability in an emergency management setting based on an analysis of accidents and proposed that vulnerability represents a measure of systemic risk exposure and its sensitivity to perceptual and stressrelated factors. Song et al. [22-24] conducted an in-depth study on the vulnerability of safety emergency management for urban rail transit systems through vulnerability factor identification, station network vulnerability assessment, factors affecting electrical fires, and vulnerability to large passenger flow disturbances. It is also noted that vulnerability assessment is an important part of vulnerability research, and related research has achieved some good results in numerous fields. For example, Moss et al. [25] assessed the vulnerability of climate change based on a comprehensive index method. Cutter et al. [26, 27] assessed the vulnerability of human-land urban systems and climate change based on a map-overlapping method. Pei-jun [28] adopted a function model assessment method to assess disaster vulnerability. Yun-fang and Zhong-chen [29, 30] assessed environmental and water security vulnerability using a fuzzy matterelement assessment method. Smith and Tran [31] adopted risk degree analysis to assess the vulnerability of the central Atlantic region. [32] carried out mechanized construction of the fabricated arch and found that both of the construction efficiency and the safety are significantly improved. [33] laid a foundation for the application of NPR anchor cable monitoring technology to the advanced anti-inclined slope failure warning. By investigating the failure mechanism of marble under FC-CPU conditions, [34] created a theoretical basis for rock dynamic disaster prediction. The effects of fractal dimension, boundary normal stiffness, and hydraulic pressure on the evolutions of mechanical behaviors, aperture distributions, and permeability are quantitatively investigated [35]. In order to solve the difficult problem of in situ testing the surrounding rock, the surrounding rock digital drilling test system (SDT system) of underground engineering is developed, and the in situ test and bolt-grouting design assessment method of surrounding rock in underground engineering based on digital drilling is proposed [36]. A novel dynamic method is proposed for stability assessment of a high sidewall subjected to flexural toppling, by integrating our derived criterion, continuum modelling, and microseismic (MS) data [37]. Safe mining depth constitutes the key to open-pit mine development; it is significant to research the safe mining depth. Under the proposed safe mining depth condition, the slope of the northeast pit can keep its stability, laying a basis for the safe mining depth determination of similar open-pit slopes [38]. Shuicheng and Chengzhen [39] proposed the "glass heart" vulnerability assessment model based on the characteristic vulnerability element evolution model proposed by Shou-xin et al. [24] and verified its use for conducting coal mine fire vulnerability assessment. Based on their analysis, they proposed that vulnerability is the degree to which a system disturbance causes the system to deviate from its normal safety status, which may represent some extent of damage. Alternatively, vulnerability could be viewed as the ability of the system to recover its normal safety status from the negative impact of disturbances. We think that vulnerability is the degree to which a system disturbance causes the system to deviate from its normal safety status, which may represent some extent of damage.

This work takes advantage of the wide applicability of vulnerability assessment to conduct coal mine gas explosion vulnerability assessment based on the "glass heart" vulnerability assessment model. Accordingly, we construct a gas explosion vulnerability assessment index system and apply the index system toward a coal mine in Henan Province, China, as an example. Here, the original disturbance index is augmented by including the energy release index factor. The Delphi method is employed by six experts to score the index factors according to a scoring standard, and the results for the example mine are reported.

\section{2. "Glass Heart" Vulnerability Assessment Model}

2.1. Vulnerability Characteristic Element Evolution Model. Early work considered only single factors as being elements reflecting the evolution of system vulnerability [40, 41]. These elements were later expanded to two elements, which included the sensitivity of the system to interference and the adaptability of the system for moving from a state of interference to a normal operating state [42-44]. Here, the latter element is routinely denoted as fitness. Other researchers included the exposure of a system to external disturbance as a characteristic vulnerability element, which provided the three elements exposure, sensitivity, and fitness [45-47]. In contrast to these past studies, the "glass heart" vulnerability model is based on the characteristic vulnerability element evolution model illustrated in Figure 1, which, in addition to the three elements exposure, sensitivity, and fitness, is constructed by considering actual system disturbances as a disturbance element. In addition to these elements, the model also considers the complex interaction 


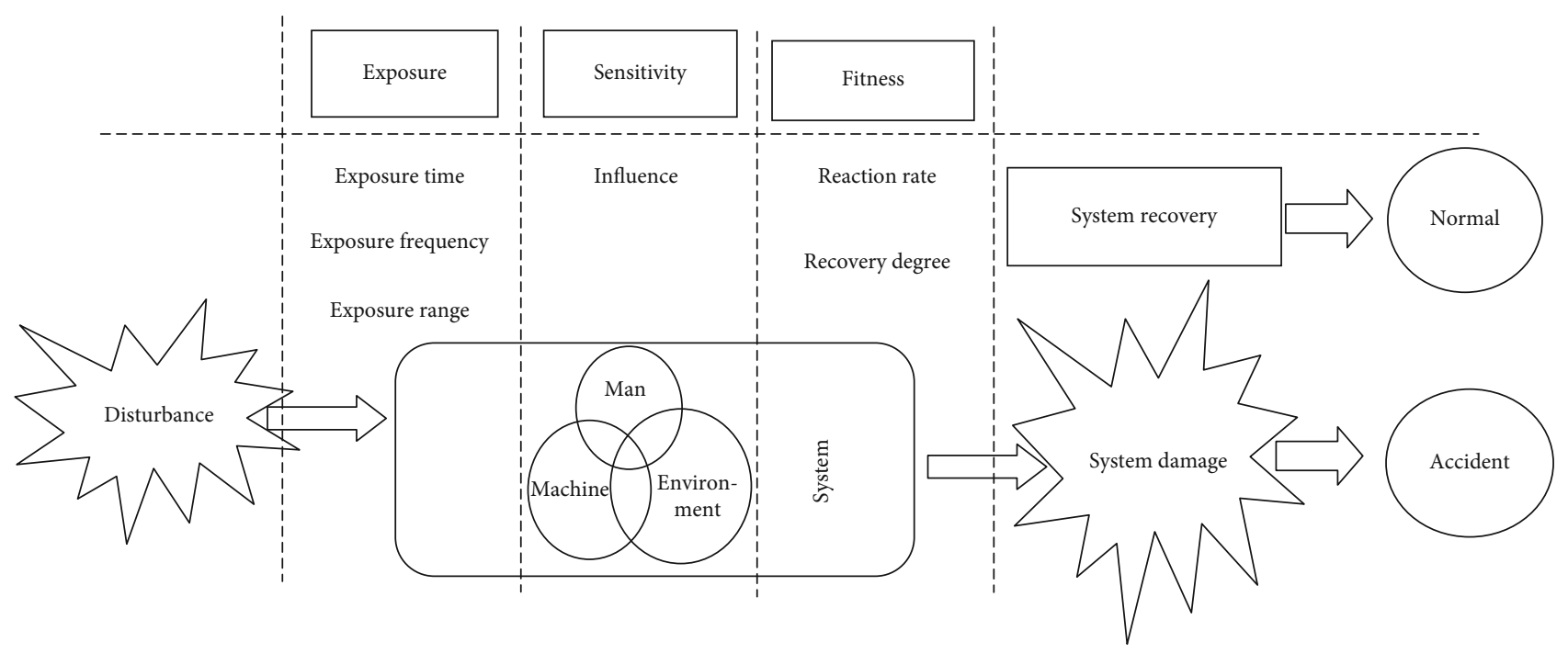

FIgURE 1: Vulnerability characteristic element evolution model.

between the four characteristic elements (i.e., exposure, sensitivity, fitness, and disturbance). Finally, a vulnerability assessment index system was established to reflect the degree to which the four characteristic elements influence system vulnerability and the degree of interaction between them.

(1) Disturbance refers to the probability and magnitude of a disturbance in the system. The disturbance comes from the combination of the accidental release of energy within the system and the hazard within the system. The disturbance is related to the potential hazard in the system and the probability of the accidental release of energy combined with the hazard. Therefore, the greater the system disturbance, the greater the vulnerability of the system

(2) Exposure refers to the degree of hazard of the "human-machine-environment-management" system. It leads to the direct cause of accidents in the system. Therefore, the greater the hazard in the system, the higher the exposure in the system. The higher the exposure in the system, the greater the vulnerability of the system, so the greater the exposure, the higher the vulnerability of the system

(3) Sensitivity refers to the degree to which the system state deviates from the normal state under the action of disturbance. It mainly refers to the reliability and stability of the system. The sensitivity is the indirect cause of the accident. The unreliability and instability of the system will increase the sensitivity of the system. The higher the sensitivity of the system, the greater the vulnerability of the system

(4) Fitness refers to the ability of a system to adapt after an accident. It mainly refers to emergency preparedness, emergency rescue, and other aspects of the system. Fitness is the positive protection function of system safety. The greater the fitness of the system, the lower the vulnerability of the system
2.2. "Glass Heart” Vulnerability Secondary Accident Model. The "glass heart" vulnerability secondary accident model is established based on the complex relationship among the four characteristic elements of system vulnerability, as shown in Figure 2. The disturbance originated from the trace intersecting of the energy release and the safety hazard in exposure. A disturbance in the system will cause the system operating state to deviate, and the system will seek to recover its standard operating state actively. The disturbance will result in a near miss when the deviation in the system operating state lies within the critical boundary of the accident. However, the system will undergo an accident (i.e., the "glass heart" is broken) when the deviation in the system operating state lies outside of the critical boundary of the accident, and the system will continue to recover its standard operating state actively after the accident. Finally, the system will be scrapped or replaced by a new system eventually if the resilience of the system is insufficient to cope with the existing vulnerability due to the destructive force of a large accident.

2.3. Vulnerability Assessment Index System. The four vulnerability characteristic elements were taken as second-grade indexes in the proposed vulnerability assessment index system, as shown in Figure 3. With respect to the risk dimension, each second-grade index was further decomposed into third-grade indexes based on the two aspects of severity and frequency.

2.4. Modified Vulnerability Index Formula. The original disturbance index formula of the "glass heart" vulnerability assessment method is given as (1) [39]:

$$
D=\sum_{x=1}^{u}\left(\sum_{i=1}^{n}\left(\left(E_{i}+\sum_{y=1}^{q} E_{i y}^{*}\right) P_{x i}\right)\right) .
$$

Here, $D$ denotes the disturbance based on a total of $u$ disturbance index factors, $E_{i}$ denotes the $n$ exposure index factors, $E_{i y}^{*}$ denotes the $q$ secondary accident exposure index 


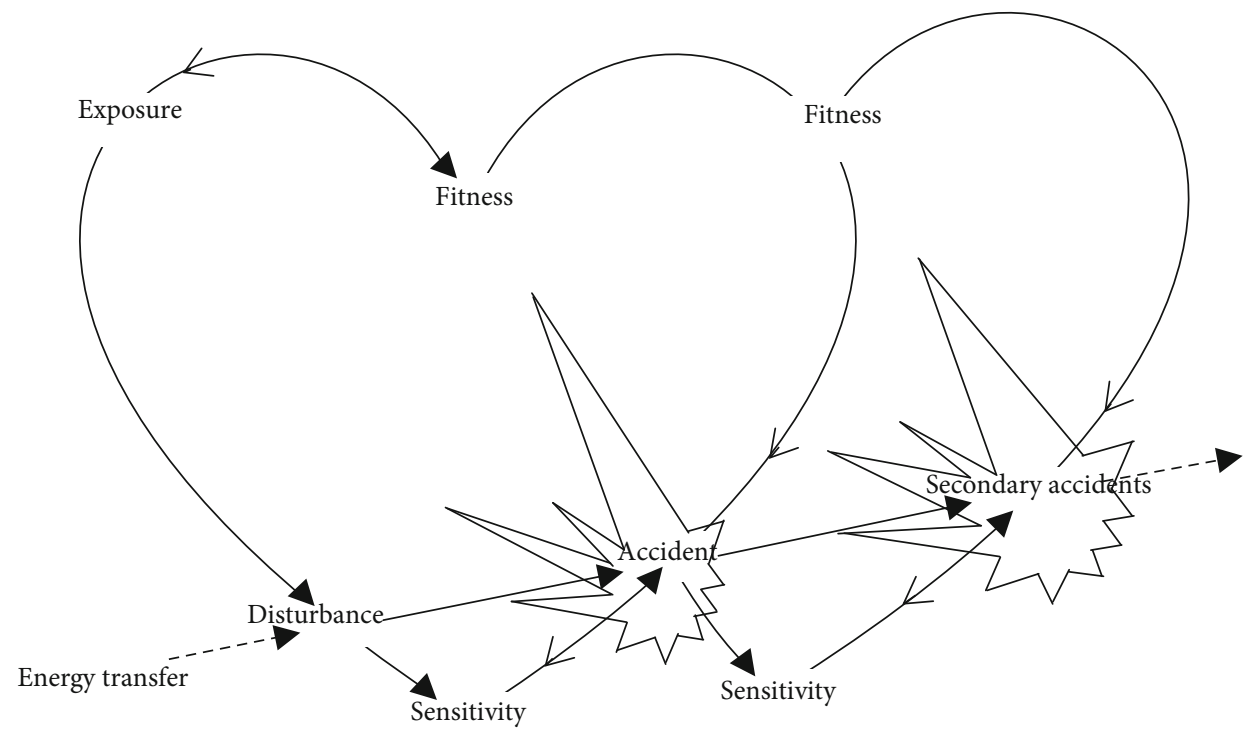

Figure 2: “Glass heart” vulnerability secondary accident model.

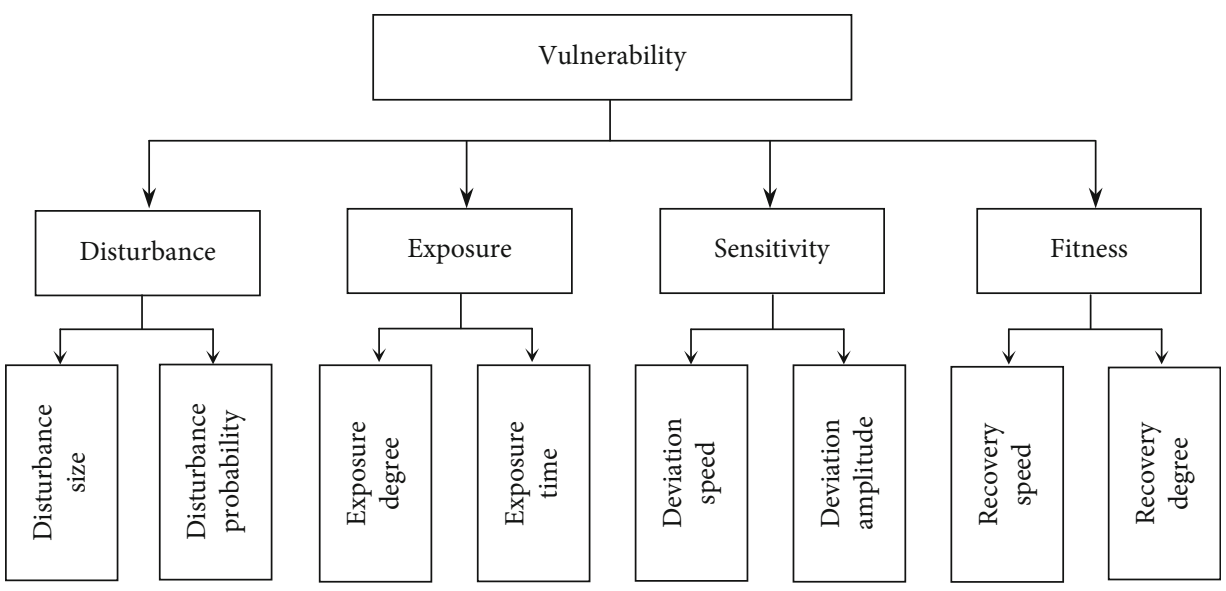

FIGURE 3: Vulnerability assessment index system.

factors after exposure index factors have led to a first accident, and $P_{x i}$ denotes the disturbance occurrence probability between the exposure index factors and the energy release index factors. However, the disturbance originated from the trace intersecting of the energy release and the safety hazard in exposure, and the energy release factor was not reflected in formula (1). This is addressed in the present work by adding the energy release factor into the disturbance influence factor, as given in

$$
E=\frac{1}{n} \sum_{i=1}^{n} E_{i}
$$

The relationship among energy release, exposure, gas explosion probability, and secondary accident probability is then given as

$$
D=100 \sum_{x=1}^{u}\left(\left(N_{x} E+\sum_{y=1}^{q}\left(N_{x} E P_{y}\right)\right) P_{x}\right) .
$$

Here, $N$ denotes energy, $P_{y}$ denotes the secondary accident occurrence probability, and $P_{x}$ denotes the disturbance occurrence probability between exposure and energy release index factors. The degree of influence of each of the four characteristic elements on system vulnerability and the degree of interaction between them can then be defined according to the following vulnerability index formula:

$$
V=\frac{\sqrt{100 \sum_{x=1}^{u}\left(\left(N_{x} E+\sum_{y=1}^{q}\left(N_{x} E P_{y}\right)\right) P_{x}\right)} \sum_{j=1}^{m} S_{j}}{\sum_{k=1}^{t} R_{k}} .
$$

Here, $V$ denotes vulnerability, $S$ denotes sensitivity, for a total of $m$ sensitivity index factors, and $R$ denotes fitness, for a total of $t$ fitness index factors.

2.5. Vulnerability Classification Standard. System vulnerability was divided into four grades according to the effect of the four characteristic elements on system vulnerability and the 
TABLE 1: Vulnerability classification standard.

\begin{tabular}{lccc}
\hline Grades & State & Range & Description \\
\hline I & Completed & $(0,0.25]$ & No casualties or property loss \\
II & Ruptured & $(0.25,0.5]$ & Likely casualties and/or property loss \\
III & Broken & $(0.5,0.75]$ & Definite casualties and/or property loss \\
IV & Comminuted & $(0.75,1.0]$ & Larger casualties and/or property loss \\
\hline
\end{tabular}

degree of interaction between them. The four grades are listed in Table 1 and characterized according to the corresponding system states, ranges of $V$ (Equation (4)), and descriptions of corresponding damage. In addition, the disturbance states corresponding to the four grades of vulnerability are more intuitively described by the state curves shown in Figure 4. Here, point $A$ represents a disturbance, and point $B$ represents the system seeking to recover its standard operating state actively.

In addition, an initial disturbance in some systems might cause secondary disturbances that damage the system further. This condition is illustrated under the present model by the system state curves shown in Figure 5 .

\section{Gas Explosion Vulnerability Assessment Index System}

The following procedure was adopted to construct a systematic, scientific, reasonable, and effective coal mine gas explosion vulnerability assessment index system.

\subsection{The Principles of Constructing the Index System}

(1) Systemic Principle. Because the various influence factors of gas explosion restrict each other and influence each other, it is necessary to use the system characteristics such as hierarchy, correlation, integrity, and flexibility to sort out these factors. Gas explosion assessment indexes should not only be representative but also cover all aspects of the influencing factors. In this way, the coal mine gas explosion risk assessment can do a good job of prepaving.

(2) Simplicity Principle. The influencing factors affecting gas explosion in coal mine involve all aspects of "human-machine-environment-management." If all the influencing factors are indexed, the workload of gas explosion risk assessment management will be very large and difficult to implement.

(3) Combining Qualitative and Quantitative Principles. The influencing factors affecting gas explosion in coal mines include quantitative and qualitative factors. Therefore, in order to obtain scientific assessment results as far as possible, we should consider some qualitative indexes that are difficult to quantify while selecting quantitative indexes. Only by taking the form of quantitative and qualitative combination can it be beneficial to fully assess the risk of gas explosion in a coal mine.

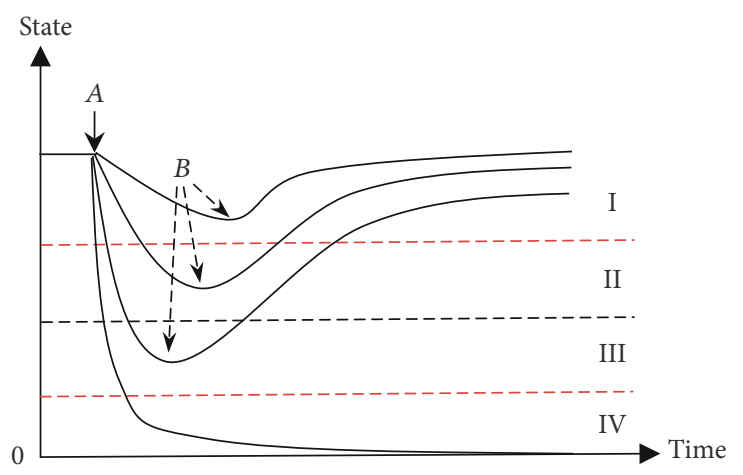

FIgURE 4: System state curves for the four vulnerability grades.

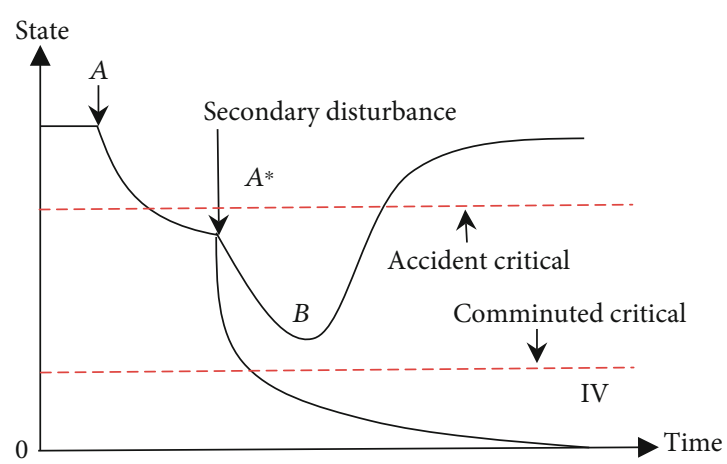

FIGURE 5: Secondary disturbance system state curves.

(4) Easy Assessment Principle. In order to realize the operability and simplicity of coal mine gas explosion assessment, reduce the workload of assessment, and improve the efficiency of gas explosion management, it is necessary to clarify the concept of each index when constructing the index system to make the assessment and quantification of the indexes simple and easy operating.

3.2. Gas Explosion Influencing Factor Analysis. Firstly, the various factors influencing coal mine gas explosion obtained in the literature were summarized and sorted, and typical coal mine gas explosion case data were collected. Secondly, interviews were conducted with coal mine employees to obtain interview data. 30 people were interviewed: 4 mine managers (mine manager, safety deputy mine manager, gas deputy mine manager, and chief engineer), 4 staff of the coal mine safety supervision department (director and deputy director of the safety supervision department and 2 engineers 


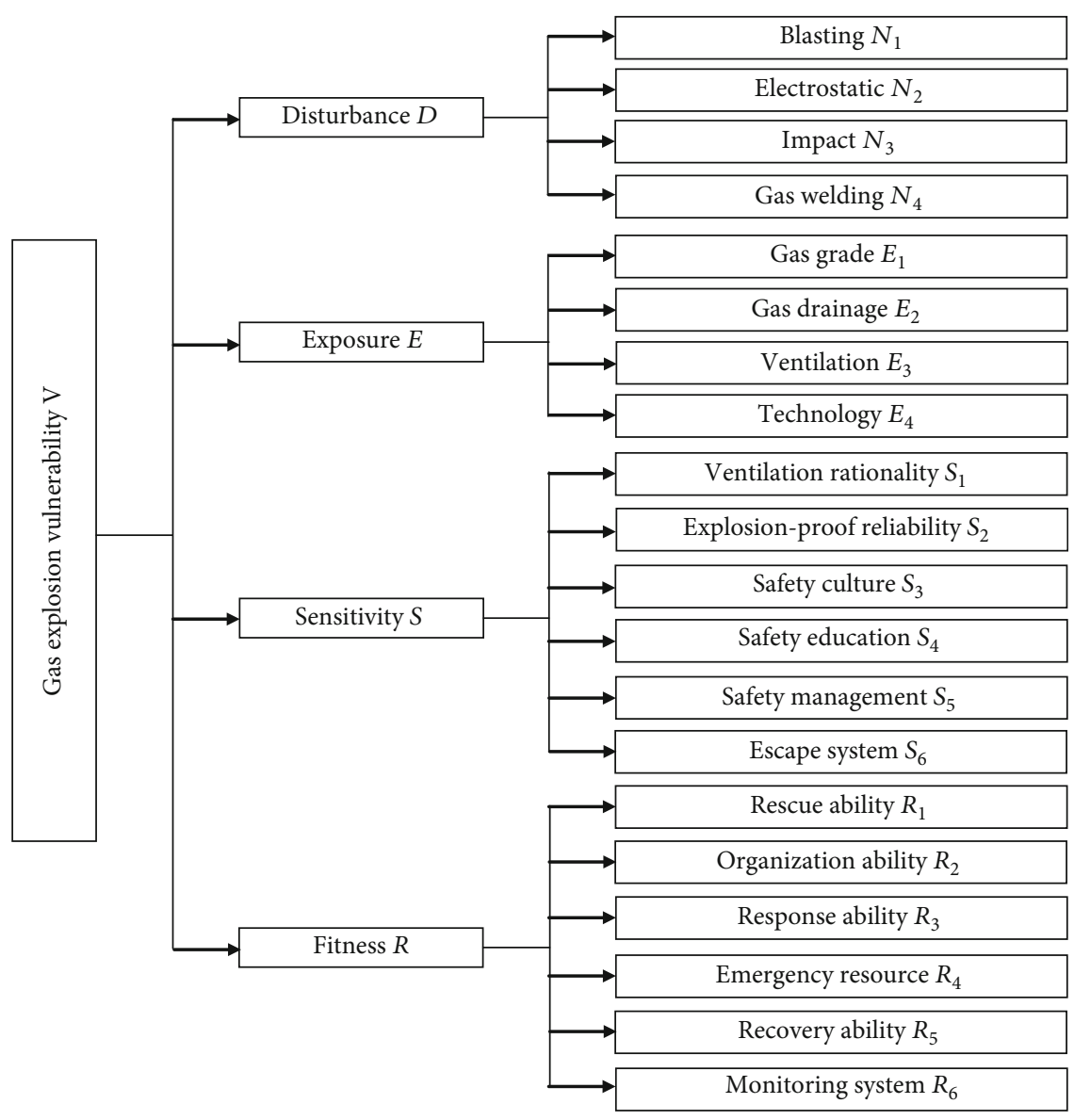

Figure 6: Gas explosion vulnerability assessment index system.

of the safety supervision department), 12 front-line production staff, and 10 experts and scholars who have been engaged in gas explosion accident research for a long time in universities.

Then, the case and interview data were triple-decoded and analyzed based on grounded theory, and the most influential factors affecting gas explosion were extracted.

3.3. Preliminary Gas Explosion Vulnerability Assessment Index System. The influencing factors were arranged, analyzed, classified, and integrated based on the $4 \mathrm{M}$ principle to obtain a preliminary gas explosion vulnerability assessment index system.

3.4. Assessment Index System Modification and Final Assessment System. The preliminary gas explosion vulnerability assessment index system was subjected to assessment by industry experts using the Delphi method, and the assessment results were employed to modify, supplement, and improve the preliminary index system.

The main operating procedures of the modification are as follows:

(1) Compile questionnaires based on the index system

(2) Distribute questionnaires to experts in the field
(3) Collect and analyze the questionnaire data to verify whether the experts' intentions for each index is unified

(4) If the experts' intention is not unified, compile a new questionnaire based on the amendments of the experts in the previous round and then conduct a new round of questionnaire survey until the intentions of the experts are unified

The final gas explosion vulnerability assessment index system is shown in Figure 6. We note that the disturbance element included 4 index factors, the exposure element included 4 index factors, the sensitivity element included 6 index factors, and the fitness element included 6 index factors.

\section{Gas Explosion Vulnerability Assessment and Case Analysis}

We conducted gas explosion vulnerability assessment index weight determination for a coal mine in Henan Province, China, based on the verification method of the "glass heart" vulnerability assessment method. The coal mine is a stateowned mine, one of the backbone production mines of Zhengzhou Coal Industry (Group) Co., Ltd. Now, the 
TABle 2: Accident probability standard [48].

\begin{tabular}{lc}
\hline Probability & Frequency $P /($ times $\cdot a-1)$ \\
\hline Likely & 0.1 \\
Common & 0.01 \\
Occasional & 0.001 \\
Seldom & 0.0001 \\
Very rarely & 0.00001 \\
Unlikely & 0.000001 \\
\hline
\end{tabular}

approved production capacity is 1 million tons. The characteristics of the coal mine are in line with the mainstream characteristics of most coal mines in China, and gas explosion accidents have occurred, so it is reasonable to choose the coal mine. The vulnerability index weight was obtained by scoring the results of expert responses. Finally, the vulnerability grade was obtained.

4.1. Expert Score Standard. We invited six experienced experts to score the vulnerability index weight standard listed in Table 2.

4.2. Expert Score Results. The gas explosion vulnerability index score results obtained by the experts are listed in Table 3. The energy release and gas concentration over the standard probability score results obtained by the experts are listed in Table 4. An analysis of the literature and results of expert interviews indicated that primary mine gas explosions would lead to secondary accidents, including fire accidents and dust explosions, which are herein denoted as $y=1$ and $y=2$, respectively. The score results obtained by the experts for the secondary accident probability are listed in Table 5.

4.3. Gas Explosion Vulnerability Index Score Results. The high- and low-gas explosion vulnerability scoring results obtained from the experts were removed, and the average of the remaining results was employed as the value of each vulnerability index. The processed gas explosion vulnerability index results are listed in Table 6.

4.4. Probabilities of Primary and Secondary Accidents. The probabilities of primary gas explosion and secondary fire and dust explosion accidents were scored by experts according to the scoring standard. The final probability values were the modes taken by the experts' number. The scoring results are listed in Table 7.

\section{Gas Explosion Vulnerability Grade Calculation Results}

The scoring results were employed in conjunction with formulas (2), (3), and (4) to obtain an overall gas explosion vulnerability for the coal mine considered.

Substituting the values of exposure indexes $E_{1}-E_{4}$ in Table 6 into formula (2) yields a value of 0.45 for the exposure $(E)$.

Substituting the values of disturbance indexes $N_{1}-N_{4}$ in Table 6 and the probabilities of primary gas explosion and
TABLE 3: Gas explosion vulnerability index score results obtained from experts.

\begin{tabular}{lcccccc}
\hline Index & 1 & 2 & 3 & 4 & 5 & 6 \\
\hline$N_{1}$ & 0.7 & 0.6 & 0.6 & 0.65 & 0.7 & 0.6 \\
$N_{2}$ & 0.3 & 0.4 & 0.3 & 0.3 & 0.3 & 0.4 \\
$N_{3}$ & 0.2 & 0.2 & 0.1 & 0.25 & 0.3 & 0.2 \\
$N_{4}$ & 0.5 & 0.6 & 0.5 & 0.5 & 0.5 & 0.6 \\
$E_{1}$ & 0.55 & 0.5 & 0.5 & 0.6 & 0.45 & 0.6 \\
$E_{2}$ & 0.4 & 0.45 & 0.4 & 0.4 & 0.6 & 0.5 \\
$E_{3}$ & 0.5 & 0.5 & 0.4 & 0.45 & 0.5 & 0.5 \\
$E_{4}$ & 0.3 & 0.4 & 0.3 & 0.3 & 0.4 & 0.3 \\
$S_{1}$ & 0.2 & 0.3 & 0.2 & 0.25 & 0.3 & 0.3 \\
$S_{2}$ & 0.4 & 0.4 & 0.5 & 0.6 & 0.6 & 0.5 \\
$S_{3}$ & 0.5 & 0.4 & 0.4 & 0.4 & 0.8 & 0.4 \\
$S_{4}$ & 0.5 & 0.4 & 0.5 & 0.3 & 0.4 & 0.5 \\
$S_{5}$ & 0.3 & 0.4 & 0.4 & 0.4 & 0.4 & 0.4 \\
$S_{6}$ & 0.6 & 0.5 & 0.6 & 0.5 & 0.5 & 0.5 \\
$R_{1}$ & 0.5 & 0.5 & 0.5 & 0.5 & 0.5 & 0.5 \\
$R_{2}$ & 0.5 & 0.6 & 0.4 & 0.6 & 0.4 & 0.6 \\
$R_{3}$ & 0.5 & 0.6 & 0.5 & 0.6 & 0.6 & 0.6 \\
$R_{4}$ & 0.6 & 0.6 & 0.6 & 0.65 & 0.6 & 0.7 \\
$R_{5}$ & 0.4 & 0.5 & 0.5 & 0.4 & 0.5 & 0.5 \\
$R_{6}$ & 0.55 & 0.6 & 0.6 & 0.5 & 0.5 & 0.6 \\
\hline & & & & & &
\end{tabular}

TABLE 4: Energy release and gas concentration over the standard probability obtained from experts.

\begin{tabular}{lcccccc}
\hline Probability & 1 & 2 & 3 & 4 & 5 & 6 \\
\hline$P_{x}=1$ & 0.01 & 0.01 & 0.01 & 0.01 & 0.001 & 0.01 \\
$P_{x}=2$ & 0.001 & 0.001 & 0.01 & 0.01 & 0.001 & 0.001 \\
$P_{x}=3$ & 0.001 & 0.001 & 0.001 & 0.01 & 0.001 & 0.001 \\
$P_{x}=4$ & 0.001 & 0.01 & 0.01 & 0.001 & 0.01 & 0.01 \\
\hline
\end{tabular}

TABLE 5: Secondary accident probability score results obtained from experts.

\begin{tabular}{lcccccc}
\hline Probability & 1 & 2 & 3 & 4 & 5 & 6 \\
\hline$P_{y}=1$ & 0.01 & 0.01 & 0.01 & 0.001 & 0.001 & 0.01 \\
$P_{y}=2$ & 0.001 & 0.001 & 0.001 & 0.001 & 0.001 & 0.001 \\
\hline
\end{tabular}

secondary fire and dust explosion accidents in Table 7 into formula (3) yields a value of 0.553 for the disturbance $(D)$.

Finally, substituting the values of exposure indexes $E_{1}-E_{4}$, sensitivity indexes $S_{1}-S_{6}$, and fitness indexes $R_{1}-R_{6}$ in Table 6 into formula (4) yields a value of 0.431 for the gas explosion vulnerability.

Accordingly, we can conclude that the example coal mine has a grade II vulnerability to gas explosion. 
TABLE 6: Gas explosion vulnerability index score results obtained from experts.

\begin{tabular}{lccccc}
\hline Index & Value & Index & Value & Index & Value \\
\hline$N_{1}$ & 0.642 & $E_{4}$ & 0.333 & $R_{1}$ & 0.5 \\
$N_{2}$ & 0.333 & $S_{1}$ & 0.258 & $R_{2}$ & 0.516 \\
$N_{3}$ & 0.208 & $S_{2}$ & 0.5 & $R_{3}$ & 0.567 \\
$N_{4}$ & 0.533 & $S_{3}$ & 0.42 & $R_{4}$ & 0.635 \\
$E_{1}$ & 0.533 & $S_{4}$ & 0.433 & $R_{5}$ & 0.467 \\
$E_{2}$ & 0.458 & $S_{5}$ & 0.383 & $R_{6}$ & 0.558 \\
$E_{3}$ & 0.475 & $S_{6}$ & 0.533 & & \\
\hline
\end{tabular}

TABle 7: Probabilities of primary gas explosion and secondary fire and dust explosion accidents.

\begin{tabular}{lcccccc}
\hline Accidents & $P_{x}=1$ & $P_{x}=2$ & $P_{x}=3$ & $P_{x}=4$ & $P_{y}=1$ & $P_{y}=2$ \\
\hline Probability & 0.01 & 0.001 & 0.001 & 0.01 & 0.01 & 0.001 \\
\hline
\end{tabular}

\section{Result Verification}

(1) After consulting the mine's data, it is found that the mine is identified as a low-gas mine. Through the survey in the past 10 years, there was no gas explosion accident that caused casualties. But there have been two burning accidents caused by cable leakage, and both of these two burning accidents were discovered and extinguished in time. Therefore, the assessment method adopted in this paper is scientific and reasonable, the assessment index system is reasonable, and the vulnerability assessment results conform to the real situation of the coal mine. The assessment results of the vulnerability "glass core" model can reflect the vulnerability of coal mine gas explosion and can be widely applied in coal mine gas explosion risk assessment

(2) The coal mine employees have received the relevant safety education and safety training before taking up their posts, but because of the high mobility and low education of the miners, it is easy to cause gas explosions in other ways due to paralysis. The coal mines should strengthen the safety education and training of miners, strengthen the efforts to catch the "three violations," and improve the safety awareness of miners, to prevent the coal mine gas explosion accident caused by paralysis

(3) There have been 2 burning accidents in the mine, which were caused by cable leakage. This is consistent with the actual investigation of some cable aging situation. The repair and replacement of aging cables should be strengthened to prevent gas explosion accidents caused by cable and wire leakage

\section{Conclusions}

(1) The present work revised and improved the index formula for the "glass heart" vulnerability assessment method by adding the energy release factor to the disturbance calculation formula in combination with the characteristics of gas explosion accidents. Accordingly, a systematic, scientific, reasonable, and effective coal mine gas explosion vulnerability assessment index system was obtained

(2) The scoring results of experts for the proposed gas explosion vulnerability assessment index system provided a gas explosion vulnerability index value of 0.431 for a coal mine in Henan Province, China. Accordingly, the mine vulnerability to gas explosion was classified as grade II based on the vulnerability classification standard, indicating that the mine is likely to result in casualties and/or property loss

(3) The example mine has occurred casualties and/or property loss. A comparison of the assessment results obtained for the example mine with the actual situation indicated that the proposed vulnerability assessment result conforms to reality. This indicates that the "glass heart" vulnerability assessment method can provide a new research perspective and methodology for conducting coal mine gas explosion assessment and classification

\section{Data Availability}

The data used to support the findings of this study are available from the corresponding author upon request.

\section{Conflicts of Interest}

The authors declare no conflicts of interest.

\section{Authors' Contributions}

Conceptualization was handled by Shuicheng Tian and Pengfei Yang; investigation, methodology, and project administration were worked on by Pengfei Yang; supervision was taken care of by Shuicheng Tian and Kai Tang; and writing (original draft) and writing (review and editing) were managed by Pengfei Yang and Kai Tang.

\section{Acknowledgments}

This research was supported by the National Natural Science Foundation of China (NSFC) under Grant nos. 51874237 and U1904210 and the National Social Science Fund of China under Grant no. 20XGL025.

\section{References}

[1] X. Qingsheng and W. Yansheng, "Study on management measures optimization on gas concentration in coal mining faces based on SD," Safety in Coal Mines, vol. 50, no. 3, pp. 144149, 2019.

[2] T. Shuicheng, L. Qing, M. Wensai, F. Yao, and H. Qian, "Causal model construction of coal mine gas explosion nearmiss incidents," Safety in Coal Mines, vol. 48, no. 4, pp. 226229, 2017. 
[3] W. Hatton and M. K. Whateley, "Risk assessment applied to coal tonnage estimation in the United Kingdom," International Journal of Rock Mechanics and Mining Sciences and Geomechanics Abstracts, vol. 32, no. 6, p. 276, 1995.

[4] C. Tauziède, Z. Pokryszka, and J. P. Barriere, "Risk assessment of gas emission at the surface of French abandoned coal mines and prevention techniques," Mining Technology, vol. 111, no. 3, pp. 192-196, 2001.

[5] C. E. Fothergill, S. Chynoweth, P. Roberts, and A. Packwood, "Evaluation of a CFD porous model for calculating ventilation in explosion hazard assessments," Journal of Loss Prevention in the Process Industries, vol. 16, no. 4, pp. 341-347, 2003.

[6] B. Marek, S. Nikodem, and O. Dariusz, Gas risk evaluation method of Poland mine coal, Beijing, 2007.

[7] W. Wenchao, "Risk evaluation and cases analysis of gas in colliery," Coal Mining Technology, vol. 11, no. 1, pp. 11-13, 2006.

[8] W. Xuan, "Risk assessment of gas probability in coal mines," China Coal, vol. 37, no. 10, pp. 96-98+101, 2011.

[9] Y. A. N. Min, Analyze on Models and Application of Dynamica Overall the Dangerous of Gas Explosion on Full Mechanized Coalface, Xi'an University of Science and Technology, 2009.

[10] W. A. N. G. Yanping, The Application Study on Risk Forewarning System of Gas Explosion and Gas Discharge Based on Hazard Theory, Chongqing University, 2006.

[11] Z. H. A. N. G. Haifeng, Early Warning Model Research of Fire Damp Explosion on KJ101 Monitored Control System, Xi'an University of Science and Technology, 2008.

[12] P. Timmerman, Vulnerability, Resilience and the Collapse of Society: A Review of Models and Possible Climatic Application, Institute for Environmental Studies, Toronto, 1981.

[13] T. I. A. N. Shuicheng and Z. H. A. N. G. Chengzhen, "Overview of vulnerability based on safety science and engineering," Journal of Xi'an university of Science and Technology, vol. 38, no. 1, pp. 8-16, 2018.

[14] W. U. Qiang, Z. H. A. N. G. Zhi-long, and M. A. Ji-fu, “A new practical methodology of the coal floor water bursting evaluating I: the master controlling index system construction," Journal of China Coal Society, vol. 32, no. 1, pp. 42-47, 2007.

[15] W. Qiang, Z. Zhilong, Z. Shengyuan, and M. Jifu, "A new practical methodology of the coal floor water bursting evaluating II: the vulnerable index method," Journal of China Coal Society, vol. 32, no. 11, pp. 1121-1126, 2007.

[16] W. Qiang, X. Shuhan, P. Zhenjiang, and M. Jifu, “A new practical methodology of the coal floor water bursting evaluating III: the application of ANN vulnerable index method based on GIS," Journal of China Coal Society, vol. 32, no. 12, pp. 1301-1306, 2007.

[17] Q. Wu, J. H. Wang, D. H. Liu, F. P. Cui, and S. Q. Liu, "A new practical methodology of the coal floor water bursting evaluating IV: the application of AHP vulnerable index method based on GIS," Journal of China Coal Society, vol. 34, no. 2, pp. 233238, 2009.

[18] J. Wu, B. Zhang, W. D. Zhao, and S. J. Liu, "A new practical methodology of coal seam floor water burst evaluation $\mathrm{V}$ : the comparison study among ANN, the weight of evidence and the logistic regression vulnerable index method based on GIS," Journal of China Coal Society, vol. 38, no. 1, pp. 21-26, 2013.

[19] L. Tie-min, "Recognition of disaster causes: study of the vulnerability," Journal of Safety Science and Technology, vol. 6, no. 5 , pp. 5-10, 2010.
[20] L. Tie-min, X. Yong-li, and W. Hao, "The frequent serious accidents exposing the system vulnerability of work safety: reflection on several serious accidents in 2013," Journal of Safety Science and Technology, vol. 10, no. 4, pp. 5-12, 2014.

[21] L. Tie-min, "The frequent of fire accidents exposed the vulnerability of urban public safety system," Journal of Safety Science and Technology, vol. 7, no. 3, pp. 5-9, 2011.

[22] Y. Peng-wei, S. Shou-xin, P. W. Yuan, S. X. Song, X. Q. Dong, and X. F. Lin, "Vulnerability identification model of urban rail tran-sit system," Journal of Transportation Systems Engineering and Information Technology, vol. 14, no. 5, pp. 100-108, 2014.

[23] X. Jia, S. O. Shouxin, and Y. U. Pengwei, "Evaluation of network vulnerability of subway stations based on ANP," China Safety Science Journal, vol. 25, no. 12, pp. 129-134, 2015.

[24] S. Shou-xin, X. Chu-yang, Z. Huai-yuan, and J. Xu, "Influential factors for subway electrical fire based on vulnerability," Journal of Xi'an University of Science and Technology, vol. 36, no. 5, pp. 691-696, 2016.

[25] R. H. Moss, A. L. Brenkert, and E. L. Malone, "Vulnerability to climate change: a quantitative approach," in Pacific Northwest National Laboratory(PNNL-SA-33642), pp. 155-167, US Department of Energy, 2001.

[26] S. L. Cutter, J. T. Mitchell, and M. S. Scott, "Revealing the vulnerability of people and places: a case study of Georgetown County, South Carolina," Annals of the Association of American Geographers, vol. 90, no. 4, pp. 713-737, 2000.

[27] K. O’Brien, R. Leichenko, U. Kelkar et al., “Mapping vulnerability to multiple stressors: climate change and globalization in India," Global Environmental Change, vol. 14, no. 4, pp. 303-313, 2004.

[28] S. H. I. Pei-jun, "Theory on disaster science and disaster dynamics," Journal of Natural Disasters, vol. 11, no. 3, pp. 19, 2002.

[29] Z. Yun-fang and W. Zhong-chen, "Fuzzy analysis of urban environment risk sequence," Journal of Natural Disasters, vol. 15, no. 1, pp. 155-158, 2006.

[30] C. Hong-qi, W. Ni, S. Yi-rong, and J. C. Xie, "Application of fuzzy matter element model in evaluation of water security based on Euclid approach degree," Journal of Xi'an University of Technology, vol. 23, no. 1, pp. 37-42, 2007.

[31] E. R. Smith and L. T. Tran, "Regional vulnerability assessment for the Mid-Atlantic Region: evaluation of integration methods and assessments results," Office of Research and Development, United States Environmental Protection Agency, Research Triangle Park, NC, 2003.

[32] Q. Wang, Q. Qin, B. Jiang et al., "Mechanized construction of fabricated arches for large-diameter tunnels," Automation in Construction, vol. 124, p. 103583, 2021.

[33] Z. G. Tao, C. Zhu, M. C. He, and M. Karakus, "A physical modeling-based study on the control mechanisms of negative Poisson's ratio anchor cable on the stratified toppling deformation of anti-inclined slopes," International Journal of Rock Mechanics and Mining Sciences, vol. 138, p. 104632, 2021.

[34] Y. Wang, W. K. Feng, R. L. Hu, and C. H. Li, "Fracture evolution and energy characteristics during marble failure under triaxial fatigue cyclic and confining pressure unloading (FCCPU) conditions," Rock Mechanics and Rock Engineering, vol. 54, no. 2, pp. 799-818, 2021.

[35] B. Li, R. Bao, Y. Wang, R. Liu, and C. Zhao, "Permeability evolution of two-dimensional fracture networks during shear 
under constant normal stiffness boundary conditions," Rock Mechanics and Rock Engineering, vol. 54, no. 3, pp. 1-20, 2021.

[36] Q. Wang, H. K. Gao, B. Jiang, S. C. Li, M. C. He, and Q. Qin, "In-situ test and bolt-grouting design evaluation method of underground engineering based on digital drilling," International Journal of Rock Mechanics and Mining Sciences, vol. 138, p. 104575, 2021.

[37] A. Li, F. Dai, Y. Liu, H. B. Du, and R. C. Jiang, "Dynamic stability evaluation of underground cavern sidewalls against flexural toppling considering excavation-induced damage," Tunnelling and Underground Space Technology, vol. 112, p. 103903, 2021.

[38] Z. G. Tao, C. Zhu, M. C. He, and K. M. Liu, "Research on the safe mining depth of anti-dip bedding slope in Changshanhao Mine," Geomechanics and Geophysics for Geo-Energy and GeoResources, vol. 36, no. 6, pp. 1-20, 2020.

[39] T. Shuicheng and Z. Chengzhen, "Construction of vulnerability "glass heart" model in safety engineering," Journal of safety science and technology, vol. 14, no. 6, pp. 160-164, 2018.

[40] M. Kusenbach, J. L. Simms, and G. A. Tobin, "Disaster vulnerability and evacuation readiness: coastal mobile home residents in Florida," Mitigation and Adaptation Strategies for Global Change, vol. 11, pp. 741-764, 2006.

[41] G. Peterson, C. R. Allen, and C. S. Holling, "Ecological resilience, biodiversity, and scale," Ecosystems, vol. 1, no. 1, pp. 6-18, 1998.

[42] G. C. Gallopin, "Linkages between vulnerability, resilience, and adaptive capacity," Global Environmental Change, vol. 16, no. 3, pp. 293-303, 2006.

[43] L. He, Z. Ping-yu, and C. Ye-qing, "Concepts and assessment methods of vulnerability," Progress in Geography, vol. 27, no. 2, pp. 18-25, 2008.

[44] E. Jenelius, T. Petersen, and L. G. Mattsson, "Importance and exposure in road network vulnerability analysis," Transportation Research Part A: Policy and Practice, vol. 40, no. 7, pp. 537-560, 2006.

[45] B. Smit and J. Wandel, "Adaptation, adaptive capacity and vulnerability," Global Environmental Change, vol. 16, no. 3, pp. 282-292, 2006.

[46] N. Brooks, W. N. Adger, and P. M. Kelly, "The determinants of vulnerability and adaptive capacity at the national level and the implications for adaptation," Global Environmental Change, vol. 15, no. 2, pp. 151-163, 2005.

[47] Z. O. U. Jun, Z. H. E. N. G. Wen-wu, and Y. A. N. G. Yu-rong, "Evaluation of water resources system vulnerability in southern hilly rural region based on the GIS/RS: take Hengyang Basin as an example," Scientia Geographica Sinica, vol. 34, no. 8, pp. 1010-1017, 2014.

[48] Z. Xingkai, "Index method of mine fire risk assessment," Journal of Safety and Environment, vol. 6, no. 4, pp. 89-92, 2006. 